\title{
Curriculum coherence as perceived by district-level stakeholders in large-scale national curriculum reform in Finland
}

\author{
Jenni Sullanmaa ${ }^{a}$, Kirsi Pyhälttö ${ }^{a, b, c}$, Janne Pietarinend and Tiina Soini ${ }^{\mathrm{e}}$ \\ ${ }^{a}$ Faculty of Educational Sciences, University of Helsinki, Helsinki, Finland; \\ ${ }^{\mathrm{b}}$ Faculty of Education, University of Oulu, Oulu, Finland; ' ${ }^{\mathrm{D}}$ Department of \\ Curriculum Studies, University of Stellenbosch, Stellenbosch, South Africa; \\ ${ }^{\mathrm{d} S c h o o l}$ of Applied Educational Science and Teacher Education, University of

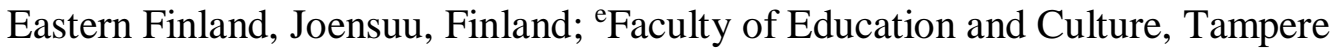 \\ University, Tampere, Finland
}

\begin{abstract}
It has been suggested that curriculum coherence is crucial in successful educational reform. However, empirical research on the topic is still scarce. This study explores how the stakeholders involved in curriculum development at the district level perceived curriculum coherence. Survey data $(n=550)$ were analysed using structural equation modelling. A confirmatory factor analysis showed that curriculum coherence consists of three complementary components: consistency of the intended direction; an integrative approach to teaching and learning; and alignment between objectives, content and assessments. Moreover, the results showed that curriculum coherence contributes to the expected impact of the reform on the school level development. The study adds to the research on curriculum reform by showing that curriculum coherence is a central determinant of the reform taking root at the school level, and by introducing a scale for measuring perceptions of curriculum coherence within the context of large-scale national curriculum reform.
\end{abstract}

Keywords: curriculum reform; curriculum coherence; school impact; school development 


\section{Funding}

This work was supported by the Ministry of Education and Culture under Grant 6600567; and the Academy of Finland under Grant 295022.

\section{Introduction}

Curriculum reform is a central tool for school development (Kelly, 2009; Luttenberg, Carpay, \& Veugelers, 2013). However, school reforms, including curriculum reform, often fail to achieve the desired impact on classroom practice. It is suggested that this may be due to a lack of coherence in the interpretations of the reform's goals and activities (Ng, 2009; Penuel, Fishman, Gallagher, Korbak, \& Lopez-Prado, 2009; Timperley \& Parr, 2005). Maintaining coherence within the elements of the curriculum, and between the curriculum and the reform process, is suggested as being the key to a successful reform (Luttenberg et al., 2013). Curriculum coherence, in terms of the alignment and continuity between and within learning goals, content, assessment and instruction, can enhance pupil performance (Newmann, Smith, Allensworth, \& Bryk, 2001; Schmidt, Wang, \& McKnight, 2005; Shwartz, Weizman, Fortus, Krajcik, \& Reiser, 2008). In addition, providing a coherent basis for building shared understandings of the goals of a curriculum (Allen \& Penuel, 2015; Datnow \& Stringfield, 2000; Hallinger \& Heck, 2002) is suggested to be important for the reform to take root. Hence, curriculum coherence is a complex construct that comprises more than alignment within the elements of the curriculum: it also depends on the consistency of the aims being pursued and the intended effects of the curriculum.

The perceived curriculum coherence among district-level stakeholders is particularly important in the Finnish curriculum reform process because these stakeholders are involved in transforming the goals and principles of the Finnish 
national core curriculum into the local curricula. It has also been proposed that support at the school district level in building and sustaining the collective capacity for generating coherence among and within schools is essential for sustainable school development (Datnow \& Stringfield, 2000; Firestone, Mangin, Martinez, \& Polovsky, 2005; Fullan, 2007; Spillane, 1996). Sustainability is comprised of context-sensitive development work, in which the preconditions of meaningful learning are considered while conducting the development process (see Coburn, 2003; Fullan, 2007). These include constructing shared understandings about the goals of the reform between different levels of the educational system, and especially local negotiations that are aimed at developing adaptable and feasible pedagogical practices in the everyday life of schools (Datnow \& Stringfield, 2000; Fullan, 2007; Sleegers, Thoonen, Oort, \& Peetsma, 2014). Sustainability also implies seeing development work as a continuing and integrated process facilitating ownership on the part of those involved (Coburn, 2003; Sleegers et al., 2014; Pyhältö, Pietarinen, \& Soini, 2014).

In this study, we explore curriculum coherence within the Finnish national core curriculum document as perceived by the educational stakeholders involved in districtlevel curriculum development. Previous research on curriculum coherence has mostly focused on subjects such as mathematics and science education, exploring coherence in terms of alignment, sequencing and progression of standards and content (e.g. Fortus, Sutherland Adams, Krajcik, \& Reiser, 2015; Schmidt et al., 2005; Schmidt \& Houang, 2012; Shwartz et al., 2008). Moreover, studies have been conducted in order to examine curriculum coherence at the school or programme level (e.g. Hatzakis, Lycett, \& Serrano, 2007; Newmann et al., 2001). Coherence has also been examined in the context of teacher education (e.g. Hammerness, 2006; Canrinus, Bergem, Klette, \& Hammerness, 2017) and within teachers' professional development programmes (e.g. 
Firestone et al., 2005; Penuel et al., 2009). However, there is a gap in research on the perceptions of curriculum coherence among educational stakeholders, particularly in the context of large-scale curriculum reform. Accordingly, our study contributes to bridging this gap in the literature by: 1) examining the anatomy of curriculum coherence as perceived by educational stakeholders in a large-scale national curriculum reform, 2) introducing an instrument for measuring the perceived curriculum coherence of the curriculum document, and 3) advancing the understanding of the relationship between the perceived curriculum coherence within the curriculum document and expectations of the reform's school impact, i.e. the potential effects and relevance of the reform work in further school-level development. We presume that curriculum coherence comprising of consistency of the intended direction, an integrative approach to teaching and learning, and alignment between objectives, content and assessments - is a precondition for the reform to have an impact on school-level development work.

\section{Core Curriculum Reform in Finland}

Curriculum reform is always situated in a particular societal context and driven by the educational policy reflecting the values and norms of the surrounding society (Rosenmund, 2000). In Finland, such drivers include equality, human rights, cultural diversity, sustainability and a democratic, egalitarian society (Finnish National Board of Education, 2014). These values also form the basis of the national core curriculum's goals. The new core curriculum for Finnish basic education was confirmed in December 2014 by the Finnish National Board of Education (FNBE), and phased implementation began in August 2016. The curriculum aims to promote collaborative classroom practices, student autonomy, and integration across school subjects. The new core curriculum integrates subject-based and competence-based learning by focusing on developing transversal competencies in addition to subject content (Finnish National 
Board of Education, 2014).

The Finnish educational steering system is based on the Basic Education Act. General educational goals and time allocations for various subjects are defined by the government. The FNBE, an independent governmental agency, is responsible for orchestrating reform of the national core curriculum approximately every ten years (Vitikka, Krokfors, \& Rikabi, 2016), and the core curriculum provides the grounding for the district-level curriculum development work (see also Mølstad, 2015). The Finnish top-down-bottom-up approach to school development (Pietarinen, Pyhältö, \& Soini, 2017) sees the local education providers as important stakeholders who are involved and engaged in the school development process (Tian \& Risku, 2019; Vitikka et al., 2016). Accordingly, local curricula are constructed within the framework of the national core curriculum by the education providers, generally as a joint curriculum for a municipality or district. The district-level curriculum reform work is typically orchestrated by steering groups consisting of municipal actors and educational practitioners from the schools. The municipalities and schools are provided with autonomy in local curriculum development to take into account contextual factors such as local needs and resources (Pietarinen et al., 2017; Vitikka et al., 2016). Stakeholders at the school district level play a central role in interpreting, integrating and transforming the general goals of the core curriculum. At their best, they are able to facilitate learning as well as the development of a shared understanding among teachers and school communities by supporting open communication and collaboration in and between the schools (Spillane, 1996; Spillane \& Thompson, 1997). School district-level collaboration in the curriculum reform process is particularly essential in Finland, where the curriculum is constructed locally by school districts or municipalities, based on the general goals set by the national core curriculum. School assessment in the Finnish 
educational system is primarily based on self-evaluation (Kumpulainen \& Lankinen, 2016) and there is no national inspection of schools or teachers (Creese, Gonzalez, \& Isaacs, 2016; Sahlberg, 2015). The local education providers are responsible for the quality of education and are encouraged to evaluate and develop the quality of their education autonomously, using internal and external evaluations (Niemi, 2016).

\section{Curriculum Coherence}

Curriculum coherence refers to the sense of direction and purpose within the curriculum, such as the connectedness between instructional activities and learning goals, and the sequential organising of learning experiences (Beane, 1995; Kelly, 2009). A coherent curriculum requires integration between everyday learning experiences and their wider purpose in different contexts (Beane, 1995). Moreover, coherence in terms of providing a basis for holistic understanding of the curriculum's aims within the different levels of the educational system is seen as essential for sustainable school development (see Fullan, 2007; Honig \& Hatch, 2004). However, research on curriculum coherence from the educational stakeholders' perspective is scarce. This study aims to contribute to a more comprehensive understanding of curriculum coherence by examining educational stakeholders' perceptions of curriculum coherence, which has been suggested to be particularly important for pupil achievement and reform implementation. The different components of perceived curriculum coherence are also explored, including consistent direction as a basis to facilitate the construction of shared understanding, focus on developing and harmonizing teaching and learning, and alignment and continuity between the elements of the curriculum. These components have previously been studied separately and it has been suggested that they are important determinants of successful curriculum reform. 
It has been proposed that providing a consistent foundation for constructing a shared vision of the curriculum's goals and aligning activities among the different stakeholders within the school and educational system is important in successful curriculum reform (Allen \& Penuel, 2015; Fuhrman, 1993; Fullan \& Quinn, 2016; Hallinger \& Heck, 2002; Honig \& Hatch, 2004). For instance, it has been suggested that clarity in the direction and purpose of school practice provides coherence and unity in the curriculum reform throughout the educational system (Smith \& O’Day, 1991). Moreover, experiencing the goals of educational reform as a holistic entity and seeing the direction as worth aiming for have been shown to be related to teachers' sense of ownership over the reform implementation (Pyhältö et al., 2014; Timperley and Parr, 2005). Thus, the curriculum should provide a foundation that facilitates building a consistent understanding of the curriculum among the national-, district- and schoollevel actors, to maintain coherence between the reform effort and the local practice of schools and teachers (Desimone, 2013; Timperley \& Parr, 2005). Maintaining a coherent approach to school improvement is seen as requiring continuous effort to adjust, involving schools and districts collaborating and negotiating their goals and strategies (Honig \& Hatch, 2004). Without clarity about the curriculum reform's aims and interaction promoting the development of coherent perceptions of the curriculum among teachers, curriculum designers and other stakeholders, the impact of the reform is likely to be compromised (Allen \& Penuel, 2015; Fernandez, Ritchie, \& Barker, 2008; Timperley \& Parr, 2005). However, the perceptions of curriculum designers, education administrators, principals and teachers often differ from each other (e.g. Fernandez et al., 2008; Ng, 2009; Timperley \& Parr, 2005; Yuen, Cheung, \& Wong, 2012). Therefore, it is important that the curriculum establishes a coherent and 
consistent direction to promote the building of shared understanding among the educational stakeholders and practitioners.

A coherent curriculum also provides an integrative framework that focuses on the development of teaching and learning, and hence, acts as a tool that will allow teachers to facilitate the development of their classroom practices (see Fullan, 2007; Newmann et al., 2001; Smith \& O'Day, 1991; Vitikka et al., 2016). It has been proposed that coherence in terms of a shared instructional framework, and the integration of activities that guide teaching and learning is important for sustainable school development (e.g. Newmann et al., 2001). For instance, holistic approach to teaching, connecting and applying learning to a larger purpose, and integration across subjects have been suggested to relate to coherence in curriculum (see Beane, 1995; Geraedts, Boersma, \& Eijkelhof, 2006). Sustainable change involves transforming educational practitioners' core beliefs and norms about teaching and learning, which requires a shared understanding and commitment to the values and principles of teaching and learning as well as capacity building at the school level (e.g. Coburn, 2003; DarlingHammond \& McLaughlin, 1995; Fullan, 2007).

Alignment between the curriculum's objectives, content, instructional methods and assessment is important for the unity and meaningfulness of pupils' learning experiences (Anderson, 2002; Squires, 2009). For example, aligning instruction with goals and assessments (e.g. Cohen, 1987; Squires, 2009) has been shown to increase pupil achievement. Moreover, the coherent sequencing and progression of content within and across grades is suggested to be related to pupils' deeper learning and understanding, as well as to achievement in international assessments in mathematics and science (Fortus et al., 2015; Schmidt et al., 2005; Shwartz et al., 2008). Thus, it is assumed that the alignment of the curriculum's different elements forms the basis for a 
coherent curriculum, but curriculum coherence also entails an explicit purpose and a clear framework for the development of teaching and learning, with which the elements in the curriculum should align.

Hence, it is suggested that curriculum coherence is comprised of several interrelated components that together regulate educational stakeholders' interpretations of the intended curriculum and further, the reform's relevance and potential impact on the further school development. This study explores curriculum coherence consisting of three complementary components within the curriculum: the consistency of the curriculum's intended direction, an integrative approach to teaching and learning, and the alignment between objectives, content and assessments.

\section{School Impact of Curriculum Reform}

The impact of curriculum reform becomes observable in the changes in everyday practices of schools, and in the experiences and activities of teachers and pupils (Fullan, 2007; Kelly, 2009). Curriculum reform that facilitates sustainable school development can have an impact on teachers' professional development, classroom interaction, learning activities implemented by teachers and active participation of pupils (e.g. Desimone, 2013; Guo, 2012; Li \& Ni, 2011). Moreover, curriculum reform that modifies the learning process and the everyday practice of schools can have the greatest impact on pupil achievement (Hopkins, 2001). An impact on pupils' learning typically requires teacher learning, i.e. acquiring new knowledge and modifying behaviour and beliefs (Fullan, 2007; Spillane, Reiser, \& Reimer, 2002). Accordingly, the implementation of curriculum reform is influenced by the curriculum's congruence with teachers' personal beliefs, the local school context, and the support and time provided for collective learning and classroom implementation, for example (Cheung \& Wong, 2011; Datnow \& Stringfield, 2000; Donnell \& Gettinger, 2015; Fernandez et al., 2008; 
Spillane et al., 2002; Yuen et al., 2012).

Achieving a shared understanding and long-term commitment to school development among the core stakeholders of a curriculum reform is essential for a successful and sustainable reform (Morris, Lo, \& Adamson, 2000; Datnow \& Stringfield, 2000). For example, in order to experience ownership over the reform implementation, teachers need to build a coherent understanding of the goals of the reform (see Allen \& Penuel, 2015; Pyhältö et al., 2014). Hence, it is also presumed that educational practitioners' perceptions of the curriculum's coherence contribute to their interpretations and intentions regarding the forthcoming curriculum implementation and the development of school practice (see Newmann et al., 2001; Penuel et al., 2009). However, we know little about the relationship between educational stakeholders' perceptions of curriculum coherence and expectations regarding the curriculum reform's impact on school development, particularly in terms of facilitating active and locally functional development work in schools.

\section{Aim of the Study}

The aim of this study was to advance the understanding of curriculum coherence by examining the anatomy of perceived curriculum coherence, introducing an instrument for measuring it, and shedding light on the relation between perceived curriculum coherence and expected school impact, in terms of facilitating the solution of problems observed in the daily life of the school and supporting active school development. Accordingly, this study examined how district-level stakeholders involved in local curriculum development work perceived the coherence of the national core curriculum document. The hypothesised model is shown in figure 1 . The following hypotheses 
were tested:

(1) Curriculum coherence comprises three interrelated components: 1) the consistency of the intended direction (see Fuhrman, 1993; Hallinger \& Heck, 2002; Honig \& Hatch, 2004), 2) an integrative approach to teaching and learning (see Newmann et al., 2001), and 3) the alignment between the objectives, content and assessments of the curriculum (e.g. Anderson, 2002; Squires, 2009) (three-factor model).

(2) The three components constitute educational stakeholders' overall perceptions of curriculum coherence (second-order factor model).

(3) The perceived overall curriculum coherence within the core curriculum document contributes to the expectations of the school level impact of the reform, i.e. the reform work's relevance and potential for continuous school development.

[Insert figure 1 about here]

\section{Research Design and Methods}

\section{Participants}

The sample $(\mathrm{n}=550)$ consisted of school district-level stakeholders who were involved in local curriculum work as members of curriculum development working groups in 12 case districts. The working groups included members from altogether 54 municipalities 
in Finland, which represented $17 \%$ of Finnish municipalities $\left(54 / 320^{1}\right)$. The municipalities represented were of various sizes, both urban and rural municipalities, and were located throughout Finland. The working groups were formed by the municipal education providers, which were responsible for constructing the local curricula within the framework of the reformed national core curriculum. The organisation of the district-level curriculum work ranged from carrying out the reform work within one municipality to working groups consisting of representatives from several neighbouring municipalities. The size of the working groups also varied, as well as the extent of involvement of school leaders, teachers and other stakeholders in the working groups (see also Tian \& Risku, 2019). However, the processes of orchestrating the district-level reform work were rather similar between districts. For example, the coordinating groups were led by educational administrators and the process involved similar thematic and subject-oriented curriculum working groups (see also Pyhältö, Pietarinen, \& Soini, 2018). The working groups were established for a certain period, i.e. for carrying out the district-level curriculum work according to an assigned timetable. Moreover, the working groups utilised varying types of expertise in developing the thematic area or school subject assigned to the group, and further, in transforming the curriculum knowledge in the district.

The data were collected using both paper and electronic surveys during spring 2016, before the curriculum implementation in schools began gradually in August 2016. Altogether 550 stakeholders participating in the district-level curriculum reform work completed the Curriculum Reform Inventory. Most of the participants were teachers ( $\mathrm{n}$ $=403 ; 73.3 \%)$ and educational leaders such as principals $(\mathrm{n}=101 ; 18.4 \%)$. The

\footnotetext{
1 The municipalities were sampled on the basis of national statistics gathered by Statistics Finland (2013).
} 
participants also included other educational experts such as municipal administrators, coordinators and student counsellors $(n=28 ; 5.1 \%)$. The majority of the respondents were women $(n=408,74 \%)$ and the minority men $(n=131,24 \%)$. Most participants $(n$ $=335,61 \%$ ) had previous experience in curriculum development work, while a minority $(n=201,37 \%)$ had none. The mean age of the participants was 46.03 years $(\mathrm{SD}=8.81 ; \operatorname{Min} / \mathrm{Max}=26 / 71)$.

\section{Measures}

The Curriculum Reform Inventory was developed for the research project to measure educational stakeholders' perceptions of large-scale curriculum reform (Pietarinen et al., 2017), and it was originally pre-tested and commented on by two experienced stakeholders involved in the core curriculum process. In this study, the curriculum coherence scale was utilized for measuring the perceived coherence regarding the direction and purpose within the core curriculum document (i.e. a content-oriented approach to the written curriculum document). In addition, the school impact scale was used for measuring the perceived potential of the curriculum reform work to trigger school development (i.e. a process-oriented approach to the curriculum work).

The curriculum coherence scale (17 items) was designed to measure the perceived coherence within the written core curriculum, as well as its goals, purpose, and the framework for developing teaching and learning (Pietarinen et al., 2017). Only one coherence sub-scale measuring perceived alignment particularly between learning goals and assessment methods had previously been validated with a sample of statelevel school administrators (Pietarinen et al., 2017). Accordingly, the structure of the coherence scale, examined within school district-level stakeholders, is introduced in this study for the first time. 
The school impact scale (6 items) measures the potential impact of the curriculum reform work on further school-level development. It measures the perceived relevance of the on-going curriculum work for resolving challenges in everyday school development work, such as committing the school level practitioners to the development work, helping them to develop locally functional solutions for organizing teaching, and solving problems faced at the school level. The scale reflects the values of Finnish basic education, such as the involvement of practitioners, and continuous school development (Pietarinen et al., 2017). The school impact scale used in this study was adapted from the scale by Pietarinen et al. (2017).

All items on the scales were rated on a 7-point Likert scale ranging from 1 (fully disagree) to 7 (fully agree). The final versions of the scales are shown in Appendix 1. The percentage of missing data per item ranged from $0.7 \%$ to $4.4 \%$.

\section{Analysis}

The hypothesised models were tested using structural equation modelling to determine the extent to which the models were consistent with the data (Byrne, 2012; Muthén \& Muthén, 1998-2015). Mplus version 7.4 was used in the analysis (Muthén \& Muthén, 1998-2015). The models were estimated using an MLR procedure, which produces maximum likelihood estimates with standard errors and Chi-square test statistics that are robust to non-normality (Muthén \& Muthén, 1998-2015), and the full information maximum likelihood method, utilising all the available information in the data (Schafer \& Graham, 2002). The goodness-of-fit of the estimated standardised model was evaluated using the Chi-square test, comparative fit index (CFI), Tucker-Lewin index (TLI), root mean square error of approximation (RMSEA) and standardised root mean square error of approximation (SRMR). Item reliability was examined by estimating the 
reliability coefficients (R-squared; Appendix 1) and the structural validity by estimating the standardised factor loadings (Hair, Black, Babin, \& Anderson, 2014).

\section{[Insert table 1 about here]}

Three alternative models of curriculum coherence - one-factor, three correlated factors, and second-order factorial structure - were tested by a confirmatory factor analysis (table 1). The single-factor model did not fit the data well, and the three-factor model fitted the data better on the basis of the goodness-of-fit indices. The hypothesized second-order factor model with three factors is a just-identified model, and thus it was not possible to compare it with the three-factor primary model using the goodness-of-fit indices (Byrne, 2012; Chen, Sousa, \& West, 2005). However, as the correlations between the factors in the three-factor model were substantial $(r=.75-.82)$, and a higher order factor was hypothesised to explain the relations between the lower order factors, the second-order measurement model was chosen for the subsequent analyses (Chen et al., 2005). Accordingly, the scale consists of three distinctive components, which comprise the overall measure of curriculum coherence. In the final measurement model, residuals of two items of the alignment factor were allowed to covariate due to the similarity of the items.

The internal consistency of the scales was examined by the factor determinacies and Cronbach's alphas (Appendix 1). Discriminant validity was examined by comparing the square root of the average variance extracted (AVE) for each construct with the correlations between the different constructs (Hair et al., 2014). Mean scores 
for each factor were constructed and analysed in terms of descriptive statistics, such as means and correlations.

\section{Results}

\section{Curriculum Coherence}

The results showed that the final second-order measurement model of curriculum coherence fitted the data, confirming hypotheses 1 and 2 (figure 2). Curriculum coherence was comprised of three complementary components: 1) consistency of the intended direction, 2) an integrative approach to teaching and learning, and 3) alignment between objectives, content and assessments.

[Insert figure 2 about here]

Consistency of the intended direction $(\mathrm{CON})$ implies that the core curriculum provides a consistent and functional direction for the school, for example, in clarifying the mission of the teacher and the school, condensing the most important goals of the school, and providing a clear foundation for local curriculum work. In turn, the integrative approach to teaching and learning (INT) focuses on the coherence of the core curriculum in terms of providing new knowledge for harmonising teaching practices, such as facilitating the development of engaging teaching methods and assessment that supports active learning. The alignment between objectives, content and assessments (ALI) component is characterised by acknowledging the pupils' age range and the continuity within subjects, as well as coherence between objectives, content, teaching 
methods and assessments in all disciplines. The three complementary components comprise the latent factor for measuring the overall perceptions of curriculum coherence in the curriculum document.

\section{[Insert table 2 about here]}

The results (table 2) showed that the stakeholders responsible for the curriculum work at the district-level perceived that the core curriculum was coherent in terms of an integrative approach to teaching and learning $(\mathrm{M}=5.23)$. Thus, the core curriculum was seen to facilitate coherent understanding about the core practices of teaching and learning, for example, encouraging teachers to use activating and engaging teaching methods and to increase the harmonisation of teaching. The consistency of the intended direction, i.e. the way in which the core curriculum supports and clarifies the aims of the school, was perceived to be slightly lower $(M=4.34)$ than the integrative approach to teaching and learning. The objectives, content and assessments within the core curriculum were also perceived as being rather well aligned by the stakeholders $(\mathrm{M}=$ 4.87). Moreover, the participants perceived that the curriculum reform process has some potential to promote further school level development $(\mathrm{M}=4.76)$, in terms of maintaining active development work in schools and helping to develop locally functional solutions for challenges faced at schools. All the correlations between the scales were positive and statistically significant in the expected directions $(\mathrm{p}<.01)$. The correlations were relatively high $(\mathrm{r}=.57-.69)$, and the results suggest that the participants' perceptions of the coherence of the written curriculum and expectations of the potential school impact of the reform work were interrelated. 


\section{Interrelation between Curriculum Coherence and School Impact}

The tested theoretical model fitted the data and confirmed hypothesis 3 by showing that curriculum coherence contributed to the expected school level impact of the curriculum reform work (figure 3).

\section{[Insert figure 3 about here]}

The results showed that curriculum coherence, in terms of consistency of the intended direction, an integrative approach to teaching and learning, and alignment between objectives, content and assessments, was related to the curriculum reform's perceived potential impact on schools $\left(\mathrm{R}^{2}=.64\right)$. The expectations of the potential effects of the reform work at the school-level development included the extent to which the reform work was perceived to have potential in committing teachers as members of the professional communities to school development work and in directing the development towards problems faced in the everyday life of schools. Accordingly, the school districtlevel stakeholders' perceptions of the coherence of the core curriculum document as a tool clarifying teachers' work and encouraging teachers to use activating teaching methods and assessment that support learning, contributed significantly to the perceived potential impact on the school practice and locally adaptive development in the forthcoming curriculum implementation.

\section{Methodological Reflection and Limitations}

It has been suggested that in examining the model fit in structural equation modelling, different types of fit indices should be used (Bollen, 1989; Hair et al., 2014). In this 
study, the tested models fitted the data well according to several fit indices (RMSEA, CFI, TLI, and SRMR), although the Chi-square test of the model fit indicated that the models did not fit the data. However, the Chi-square test may have been influenced by the relatively large sample size (Byrne, 2012; Hair et al., 2014).

The second-order factor model with three factors is a just-identified model, and therefore it was not possible to compare statistically the fit of the second-order model and the three-factor primary model with the goodness-of-fit indices (Byrne, 2012; Chen et al., 2005). However, because a) the three factors strongly correlated with each other as expected, b) the second-order latent factor was hypothesised to account for the correlations among the factors, and c) the use of the second-order model was more parsimonious in terms of the subsequent structural model, the second-order factor model was chosen for further analysis.

The structural validity was estimated by the standardised factor loadings, which were adequate between observed variables and latent variables $(\geq .50)$, and between the latent factors and the second-order factor of curriculum coherence $(>.80)$. The internal consistency of the scales was sufficient, as shown by the factor determinacies and Cronbach's alphas (Appendix 1). Discriminant validity between the school impact scale and the curriculum coherence factors was also supported, with the square root of the average variance extracted (AVE) of each construct being higher than the correlation between the different constructs (Hair et al., 2014). However, discriminant validity was not established between the alignment factor and the other two components of curriculum coherence with this method. Yet, these components were assumed to measure the same latent construct of curriculum coherence.

Hence, the validity of the curriculum coherence and school impact scales was supported, but further validation of the scales is necessary in other curriculum reform 
contexts. Use of the instruments and validation of the scales with other data sets in different contexts, for example at the school level, and with longitudinal data, is needed to further examine the validity and reliability of the scales.

Although most of the participants were teachers and other school staff, it should be noted that they do not fully represent the perceptions of all school-level actors. The participants were invited or signed up for the district-level curriculum process as part of the curriculum development working groups. Hence, they may have been more active or development-oriented individuals, and the role of the participants in the district-level working groups has involved various opportunities to discuss and make sense of the curriculum. Thus, through this experience they might have constructed more coherent perceptions of the core curriculum than school-level actors on average (see also Salminen \& Annevirta, 2016). Accordingly, more research is needed to explore how curriculum coherence and school-level impact of the reform is perceived at the school level where the context-specific complexity may increase, and whether the perceptions differ from those involved in the district-level curriculum work.

Moreover, it is important to note that the new curriculum had not yet been implemented in the schools when the data were collected in spring 2016. Thus, the perceptions of the potential effects on school level development of the reform work are estimations by the participating district-level stakeholders, who were still in the process of completing the local curricula. However, the results suggest that their perceptions of the national core curriculum document as a coherent entity were related to their expectations of the reform's potential effects on the school development. These expectations regarding the impact might further facilitate the development work in the local contexts. 


\section{Discussion}

The present study introduced a scale for measuring the perceptions of curriculum coherence, a construct that has previously been studied primarily in terms of the alignment, sequencing and progression of content within the curriculum, or in the context of school or programme-level curricula. However, it is suggested that coherence in a broader sense is an essential factor for sustainable school development (see e.g. Fullan \& Quinn, 2016; Honig \& Hatch, 2004; Newmann et al., 2001). The findings indicated that curriculum coherence consists of three complementary components: consistency of the intended direction, an integrative approach to teaching and learning, and alignment between objectives, content and assessments. Accordingly, the results imply that a coherent large-scale curriculum should provide the following three interrelated core elements:

Firstly, a coherent curriculum should provide consistency in the intended direction of the curriculum by clarifying, developing and summing up the most important goals and missions of the teachers and schools. This finding supports the suggestion that focusing on clear educational goals is essential in building coherence in educational systems (Fullan \& Quinn, 2016; Newmann et al., 2001). Studies have suggested that developing a mutual understanding of the curriculum reform and its goals between the change initiators and teachers is necessary for successful change (Fernandez et al., 2008; Timperley \& Parr, 2005). It has also been suggested that a clear and holistic understanding of the goals of the reform is related to teachers' experience of responsibility and ownership of the curriculum reform (Pyhältö et al., 2014).

Secondly, the findings imply that curriculum coherence entails an integrative approach to teaching and learning, which facilitates the development of the core 
practices of teaching and learning in a harmonized way. In Finland, the curriculum has traditionally concentrated on developing teaching and learning, and teachers are recognised and highlighted as the most influential factor in a reform process having an effect on student learning (Sahlberg, 2015). The new national core curriculum focuses on ubiquitous learning, activating teaching methods, pupil engagement as well as collaborative and integrative learning across subjects (Finnish National Board of Education, 2014). Hence, integration between subjects and contexts, and collaboration in the school community, are required from teachers. Curriculum coherence in terms of an integrative approach to teaching and learning is in line with literature suggesting that clear and shared values with respect to pupil learning, and a sufficiently shared instructional framework that supports the development of teaching and learning, are essential for sustainable school development and pupil achievement (Fullan \& Quinn, 2016; Newmann et al., 2001).

Thirdly, curriculum coherence was found to include alignment between the objectives, content and assessment. In previous studies, the alignment and sequencing of the curriculum have been associated with increased pupil performance (Fortus et al., 2015; Newmann et al., 2001; Schmidt et al., 2005; Shwartz et al., 2008). Hence, our results contribute to the literature by showing that alignment as a part of curriculum coherence is also related to educational stakeholders' perceptions of curriculum reform's potential effects on further development at the school level. Alignment as an element of curriculum coherence is linked to the other components. The consistency of the intended direction and an integrative approach to teaching and learning require that the curriculum's elements are in line with each other and are aimed in the same direction. 
The district-level stakeholders in our study perceived the core curriculum document to be rather coherent in terms of all three components. The integrative approach to teaching and learning as a component of curriculum coherence was perceived to be slightly more evident in the core curriculum than the consistency of the intended direction. This may imply that the core curriculum was perceived to provide a clear grounding for the development of teaching and learning in the local curricula, but that the intended direction of the curriculum may not have been perceived as being as clear, consistent or effective. Even though only a slight drop was observed regarding the consistency of the intended direction, it suggests that more attention should be paid to stakeholders at different levels developing a shared understanding about and agreeing on the main aims and direction of the curriculum.

Finally, the perceived curriculum coherence of the written core curriculum document contributed to the potential impact that the reform process was expected to have on school-level development. This indicates that a high degree of perceived coherence within the curriculum document contributes to the perceived impact of the reform work on the school level, in terms of helping to resolve challenges in the local school development work and committing teachers to working on developing the school. Accordingly, the results imply that curriculum coherence is a central determinant of the reform taking root at the school level, and hence promotes sustainable school development.

The results emphasise the significance of curriculum coherence in large-scale curriculum reform by implying that curriculum coherence is crucial for sustainable school development. Hence, ensuring the coherence of the normative core curriculum document at the state level and facilitating active sensemaking and construction of coherent understanding at the district level would appear to facilitate the educational 
stakeholders' perceptions of the potential effects of curriculum work at the local level, and further, to increase the potential of the curriculum reform to trigger real change in the everyday practices of schools. However, coherence is comprised of several complementary components, which implies that building coherence means enhancing all the elements simultaneously throughout the educational system. Concentrating merely on one aspect is likely to reduce the sustainability of the school development. For example, aiming only to align objectives, content and assessments, while ignoring the solid basis for constructing shared understanding about the intended direction of the reform may result in a mere technical curriculum in the worst case, which neither facilitates learning nor utilises the expertise of those involved in the process (see also Fullan \& Quinn, 2016; Honig \& Hatch, 2004).

The present study contributes to the research on curriculum reform by introducing a scale for measuring perceived curriculum coherence in the context of large-scale curriculum reform, and hence provides a tool for determining reform progress in terms of perceived curriculum coherence. The scale can be used as a tool to promote and steer research-based curriculum reform work at different levels of the educational system, since it provides diagnostic information on how the stakeholders involved in a reform perceive the components of curriculum coherence. The study further showed that perceived curriculum coherence, including its three key components, contributes to the potential impact that the reform work is perceived to have on school-level development. In terms of school development, the findings imply that the coherence of the written curriculum, including all three components, is a central determinant of what can be attained in developing the school practices, for example, what instructional methods are adapted and what innovations are applied in the classrooms. 
Accordingly, the results of the study imply the following:

- Curriculum coherence is an important determinant of curriculum development work contributing to expectations of potential school-level effects, especially in a largescale reform.

- The educational stakeholders' perceptions about the curriculum document's coherence are related to their understanding of the further development work and practice at the local level. This implies that to facilitate positive beliefs about the effects of the reform work at the school level, effort needs to be invested in facilitating the construction of coherent understanding about the curriculum document.

- To facilitate curriculum coherence, effort should be invested in enhancing all three components simultaneously: consistency of the intended direction, an integrative approach to teaching and learning, and alignment between objectives, content and assessment. Collaboration and negotiation about the content and criteria crucial to each component of curriculum coherence is necessary between the different stakeholders across the levels of the educational system, including practitioners at state, district and school levels.

Further research is needed to examine the components of coherence and the role of perceived curriculum coherence in other contexts, as well as to determine how curriculum coherence is connected to actual changes at the school level. For example, this study showed that the intended direction of the core curriculum, i.e. the extent to which the core curriculum supports, develops and clarifies the work of schools and teachers, was perceived as a more challenging or less agreeable component of curriculum coherence from the district-level stakeholders' point of view, compared to the integrative approach to teaching and learning, and alignment between the objectives, 
content and assessments of the curriculum. This may indicate a hierarchy between these components of curriculum coherence that might regulate and contribute to teachers' willingness to implement the curriculum and change their beliefs and practices. Accordingly, the significance and complexity of curriculum coherence in terms of making sense of the core curriculum document at the school level should be further studied. 


\section{References}

Allen, C. D., \& Penuel, W. R. (2015). Studying teachers' sensemaking to investigate teachers' responses to professional development focused on new standards. Journal of Teacher Education, 66(2), 136-149.

Anderson, L. W. (2002). Curricular alignment: A re-examination. Theory into Practice, 41(4), 255-260.

Beane, J. A. (Ed.). (1995). Toward a coherent curriculum. Alexandria, VA: ASCD.

Bollen, K. A. (1989). Structural equations with latent variables (1. ed.). New York: Wiley.

Byrne, B. M. (2012). Structural equation modeling with Mplus. New York: Routledge.

Canrinus, E. T., Bergem, O. K., Klette, K., \& Hammerness, K. (2017). Coherent teacher education programmes: taking a student perspective. Journal of Curriculum Studies, 49(3), 313-333.

Chen, F. F., Sousa, K. H., \& West, S. G. (2005). Teacher's corner: Testing measurement invariance of second-order factor models. Structural Equation Modeling: A Multidisciplinary Journal, 12(3), 471-492.

Cheung, A. C. K., \& Wong, P. M. (2011). Effects of school heads' and teachers' agreement with the curriculum reform on curriculum development progress and student learning in Hong Kong. The International Journal of Educational Management, 25(5), 453-473.

Coburn, C. E. (2003). Rethinking scale: Moving beyond numbers to deep and lasting change. Educational Researcher, 32(6), 3-12.

Cohen, S. A. (1987). Instructional alignment: Searching for a magic bullet. Educational Researcher, 16(8), 16-20.

Creese, B., Gonzalez, A., \& Isaacs, T. (2016). Comparing international curriculum systems: The international instructional systems study. The Curriculum Journal, $27(1), 5-23$.

Darling-Hammond, L., \& McLaughlin, M. W. (1995). Policies that support professional development in an era of reform. Phi Delta Kappan, 76(8), 597-604.

Datnow, A., \& Stringfield, S. (2000). Working together for reliable school reform. Journal of Education for Students Placed at Risk, 5(1-2), 183-204.

Desimone, L. (2013). Teacher and administrator responses to standards-based reform. Teachers College Record, 115(8), 1-53. 
Donnell, L. A., \& Gettinger, M. (2015). Elementary school teachers' acceptability of school reform: Contribution of belief congruence, self-efficacy, and professional development. Teaching and Teacher Education, 51, 47-57.

Fernandez, T., Ritchie, G., \& Barker, M. (2008). A sociocultural analysis of mandated curriculum change: The implementation of a new senior physics curriculum in New Zealand schools. Journal of Curriculum Studies, 40(2), 187-213.

Finnish National Board of Education. (2014). National core curriculum for basic education 2014. Finnish National Board of Education. Publications 2016:5.

Firestone, W. A., Mangin, M. M., Martinez, M. C., \& Polovsky, T. (2005). Leading coherent professional development: A comparison of three districts. Educational Administration Quarterly, 41(3), 413-448.

Fortus, D., Sutherland Adams, L. M., Krajcik, J., \& Reiser, B. (2015). Assessing the role of curriculum coherence in student learning about energy. Journal of Research in Science Teaching, 52(10), 1408-1425.

Fuhrman, S. H. (1993). The politics of coherence. In S. H. Fuhrman (Ed.), Designing coherent educational policy (pp. 1-34). San Francisco: Jossey-Bass.

Fullan, M. (2007). The new meaning of educational change (4th ed.). New York: Teachers College Press.

Fullan, M., \& Quinn, J. (2016). Coherence: The right drivers in action for schools, districts, and systems. Thousand Oaks: Corwin.

Geraedts, C., Boersma, K. T., \& Eijkelhof, H. M. C. (2006). Towards coherent science and technology education. Journal of Curriculum Studies, 38(3), 307-325.

Guo, L. (2012). The impact of new national curricular reform on teachers. Canadian and International Education, 41(2), 87-105.

Hair, J. F., Black, W. C., Babin, B. J., \& Anderson, R. E. (2014). Multivariate data analysis (7th ed.). Harlow: Pearson.

Hallinger, P., \& Heck, R. H. (2002). What do you call people with visions? The role of vision, mission, and goals in school leadership and improvement. In K. Leithwood, \& P. Hallinger (Eds.), Handbook of research in educational leadership and administration, 2nd ed. (pp. 9-40). Dordrecht: Kluwer Academic.

Hammerness, K. (2006). From coherence in theory to coherence in practice. Teachers College Record, 108(7), 1241-1265.

Hatzakis, T., Lycett, M., \& Serrano, A. (2007). A programme management approach for ensuring curriculum coherence in IS (higher) education. European Journal of Information Systems, 16(5), 643-657. 
Honig, M. I., \& Hatch, T. C. (2004). Crafting coherence: How schools strategically manage multiple, external demands. Educational Researcher, 33(8), 16-30.

Hopkins, D. (2001). School improvement for real. London: Routledge Falmer.

Kelly, A. V. (2009). The curriculum: Theory and practice (6th ed.). Los Angeles: SAGE.

Kumpulainen, K., \& Lankinen, T. (2016). Striving for educational equity and excellence: Evaluation and assessment in Finnish basic education. In H. Niemi, A. Toom, \& A. Kallioniemi (Eds.), Miracle of education: The principles and practices of teaching and learning in Finnish schools, second revised edition (pp. 71-82). Rotterdam: SensePublishers.

Li, Q., \& Ni, Y. (2011). Impact of curriculum reform: Evidence of change in classroom practice in mainland China. International Journal of Educational Research, 50(2), 71-86.

Luttenberg, J., Carpay, T., \& Veugelers, W. (2013). Educational reform as a dynamic system of problems and solutions: Towards an analytic instrument. Journal of Educational Change, 14(3), 335-352.

Mølstad, C. E. (2015). State-based curriculum-making: Approaches to local curriculum work in Norway and Finland. Journal of Curriculum Studies, 47(4), 441-461.

Morris, P., Lo, M., \& Adamson, B. (2000). Improving schools in Hong Kong - Lessons from the past. In B. Adamson, K. Chan, \& T. Kwan (Eds), Changing the curriculum: The impact of reform on primary schooling in Hong Kong (pp. 245262). Hong Kong: Hong Kong University Press.

Muthén, L. K., \& Muthén, B. O. (1998-2015). Mplus users guide (7th ed.). Los Angeles: Muthen \& Muthen.

Newmann, F. M., Smith, B., Allensworth, E., \& Bryk, A. S. (2001). Instructional program coherence: What it is and why should it guide school improvement policy. Educational Evaluation and Policy Analysis, 23(4), 297-321.

$\mathrm{Ng}, \mathrm{S}$. W. (2009). Why did principals and teachers respond differently to curriculum reform? Teacher Development, 13(3), 187-203.

Niemi, H. (2016). The societal factors contributing to education and schooling. In $\mathrm{H}$. Niemi, A. Toom, \& A. Kallioniemi (Eds.), Miracle of education: The principles and practices of teaching and learning in Finnish schools, second revised edition (pp. 23-40). Rotterdam: SensePublishers.

Penuel, W. R., Fishman, B. J., Gallagher, L. P., Korbak, C., \& Lopez-Prado, B. (2009). Is alignment enough? Investigating the effects of state policies and professional development on science curriculum implementation. Science Education, 93(4), 656-677. 
Pietarinen, J., Pyhältö, K., \& Soini, T. (2017). Large-scale curriculum reform in Finland - exploring the interrelation between implementation strategy, the function of the reform, and curriculum coherence. The Curriculum Journal, 28(1), 22-40.

Pyhältö, K., Pietarinen, J., \& Soini, T. (2014). Comprehensive school teachers' professional agency in large-scale educational change. Journal of Educational Change, 15(3), 303-325.

Pyhältö, K., Pietarinen, J., \& Soini, T. (2018). Dynamic and shared sense-making in large-scale curriculum reform in school districts. The Curriculum Journal, 29(2), $181-200$.

Rosenmund, M. (2000). OP-ED Approaches to international comparative research on curricula and curriculum-making processes. Journal of Curriculum Studies, 32(5), 599-606.

Sahlberg, P. (2015). Finnish lessons 2.0: What can the world learn from educational change in Finland? (2nd ed.). New York: Teachers College Press.

Salminen, J., \& Annevirta, T. (2016). Curriculum and teachers' pedagogical thinking when planning for teaching. European Journal of Curriculum Studies, 3(1), 387406.

Schafer, J. L., \& Graham, J. W. (2002). Missing data: Our view of the state of the art. Psychological Methods, 7(2), 147-177.

Schmidt, W. H., \& Houang, R. T. (2012). Curricular coherence and the common core state standards for mathematics. Educational Researcher, 41(8), 294-308.

Schmidt, W. H., Wang, H. C., \& McKnight, C. C. (2005). Curriculum coherence: An examination of US mathematics and science content standards from an international perspective. Journal of Curriculum Studies, 37(5), 525-559.

Shwartz, Y., Weizman, A., Fortus, D., Krajcik, J., \& Reiser, B. (2008). The IQWST experience: Using coherence as a design principle for a middle school science curriculum. The Elementary School Journal, 109(2), 199-219.

Sleegers, P. J. C., Thoonen, E. E. J., Oort, F. J., \& Peetsma, T. T. D. (2014). Changing classroom practices: The role of school-wide capacity for sustainable improvement. Journal of Educational Administration, 52(5), 617-652.

Smith, M., \& O'Day, J. A. (1991). Systemic school reform. In S. H. Fuhrman \& B. Malen (Eds.), The politics of curriculum and testing (pp. 233-268). Bristol, PA: Falmer.

Spillane, J. P. (1996). School districts matter: Local educational authorities and state instructional policy. Educational Policy, 10(1), 63-87. 
Spillane, J. P., \& Thompson, C. L. (1997). Reconstructing conceptions of local capacity: The local education agency's capacity for ambitious instructional reform. Educational Evaluation and Policy Analysis, 19(2), 185-203.

Spillane, J. P., Reiser, B. J., \& Reimer, T. (2002). Policy implementation and cognition: Reframing and refocusing implementation research. Review of Educational Research, 72(3), 387-431.

Squires, D. A. (2009). Curriculum alignment: Research-based strategies for increasing student achievement. Thousand Oaks: Corwin.

Statistics Finland (2013). Municipalities and regional divisions based on municipalities (Vol. 28), Statistics Finland, Helsinki.

Tian, M. \& Risku, M. (2019). A distributed leadership perspective on the Finnish curriculum reform 2014, Journal of Curriculum Studies, 51(2), 229-244.

Timperley, H., \& Parr, J. (2005). Theory competition and the process of change. Journal of Educational Change, 6(3), 227-251.

Vitikka, E., Krokfors, L., \& Rikabi, L. (2016). The Finnish national core curriculum. In Niemi, H., Toom, A., \& Kallioniemi, A. (Eds.), Miracle of education: The principles and practices of teaching and learning in Finnish schools, second revised edition (pp. 83-90). Rotterdam: SensePublishers.

Yuen, T. W. W., Cheung, A. C. K., \& Wong, P. M. (2012). A study of the impact of the first phase of the curriculum reform on student learning in Hong Kong. International Journal of Educational Management, 26(7), 710-728. 


\section{Appendix 1}

The scales, items, Cronbach alphas, factor determinacies, and item reliability coefficients $\left(\mathrm{R}^{2}\right)$ for curriculum coherence and school impact scales.

\begin{tabular}{lcr}
\hline Scales* & \multicolumn{1}{c}{ Cronbach's $\boldsymbol{\alpha}$ Factor dete } \\
\hline Curriculum coherence (second-order factorial structure) & .92 & .93 \\
Consistency of the intended direction & .86 & .94
\end{tabular}

\section{(In) The national core curriculum...}

Con11: clarifies the entity of a teacher's job $\quad .58$

Con12: supports the teaching of the essential material in various subjects

Con13: delimits the duty of the school in a sensible manner $\quad .37$

Con14: is clear and well organised $\quad .52$

Con15: successfully sums up the most important goals for the operation of the school $\quad .50$

Con16: constitutes an aligned foundation for the local curricular work

Integrative approach to teaching and learning

.74

.91

(In) The national core curriculum...

Int21: encourages teachers to use activating and engaging teaching methods

Int22: encourages teachers to use assessment methods that support learning

Int23: supports the harmonisation of teaching

Int24: the general section creates something new

Alignment between objectives, content and assessments

.84

.94

(In) The national core curriculum...

Ali31: the goals are in line with the assessment criteria $\quad .39$

Ali32: a subject constitutes an integral continuum $\quad .38$

Ali33: the goals are in line with contents $\quad .40$

Ali34: takes a pupil's age range into consideration $\quad .47$

Ali35: descriptions of teaching methods in various subjects are in harmony with the general goals $\quad .39$

Ali36: constitutes an integral whole $\quad .58$

Ali37: the goals of the general section are also well in evidence in the subject section $\quad .29$

School impact (single-factor factorial structure)

.87

.94

The work to reform the curriculum...

Sci1: maintains active development work at schools

Sci2: commits teachers to working on developing the school $\quad .57$

Sci3: helps the school community identify the core tasks

Sci4: directs development work to resolve problems observed in the daily life of the school

Sci5: helps people develop solutions that work at the local level for organizing teaching $\quad .68$

Sci6: promotes the resolution of many problems related to basic education at the local level $\quad .33$

*Translated from Finnish. The item scale: I fully disagree 1234567 I fully agree. 
Table 1. Goodness-of-fit statistics for the tested factorial models.

\begin{tabular}{lccccccc}
\hline Model & Chi-square & df & $\mathbf{p}$ & RMSEA [90\% CI] & CFI & TLI & SRMR \\
\hline Single-factor model & 497.57 & 119 & $<.001$ & $.076[.069, .083]$ & .86 & .84 & .055 \\
Three-factor primary model & 337.75 & 116 & $<.001$ & $.059[.052, .066]$ & .92 & .90 & .045 \\
Second-order factor model & 337.75 & 116 & $<.001$ & $.059[.052, .066]$ & .92 & .90 & .045 \\
\hline
\end{tabular}


Table 2. Means, standard deviations, correlations and alphas among the scales.

\begin{tabular}{lllll}
\hline & 1. & 2. & 3. & 4. \\
\hline (1) CON & - & & & \\
(2) INT & $.61^{* *}$ & - & & \\
(3) ALI & $.69^{* *}$ & $.66^{* *}$ & - & \\
(4) School impact & $.64^{* *}$ & $.62^{* *}$ & $.57^{* *}$ & - \\
Number of items & 6 & 4 & 7 & 6 \\
M & 4.34 & 5.23 & 4.87 & 4.76 \\
SD & 1.00 & 0.86 & 0.80 & 0.96 \\
Min & 1.17 & 1.75 & 2 & 1.33 \\
Max & 6.83 & 7 & 7 & 7 \\
$\alpha$ & .86 & .74 & .84 & .87 \\
\hline
\end{tabular}

** Significant at the .01 level. 


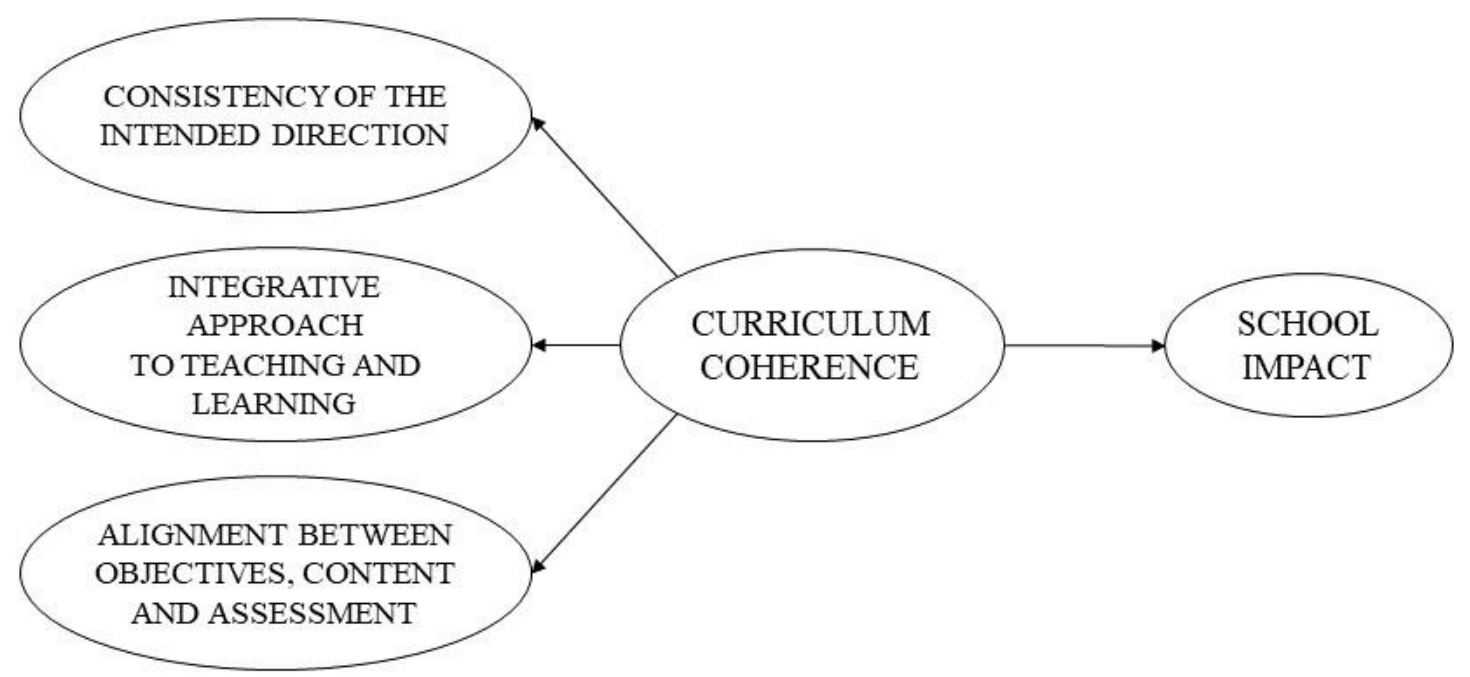

Figure 1. Hypothesised model. 


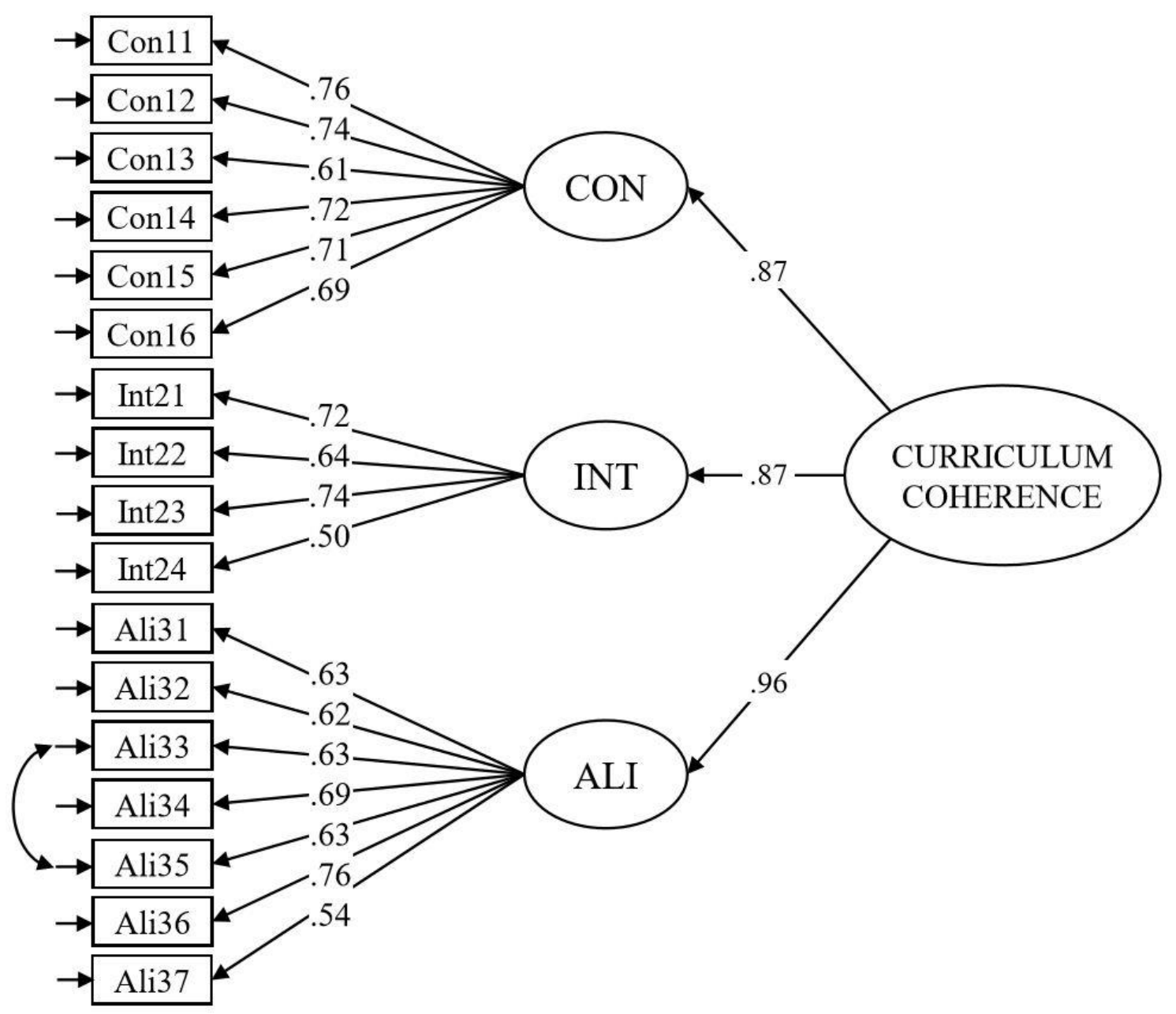

Figure 2. Components of curriculum coherence: consistency of the intended direction $(\mathrm{CON})$; integrative approach to teaching and learning (INT); and alignment between objectives, content and assessments (ALI). Standardised model: $\mathrm{x}^{2}=287.47, \mathrm{df}=115, \mathrm{p}$ $<.001 ; \mathrm{RMSEA}=.052(90 \%$ C.I. $=.045-.060) ; \mathrm{CFI}=.94 ; \mathrm{TLI}=.93 ; \mathrm{SRMR}=.043$. 


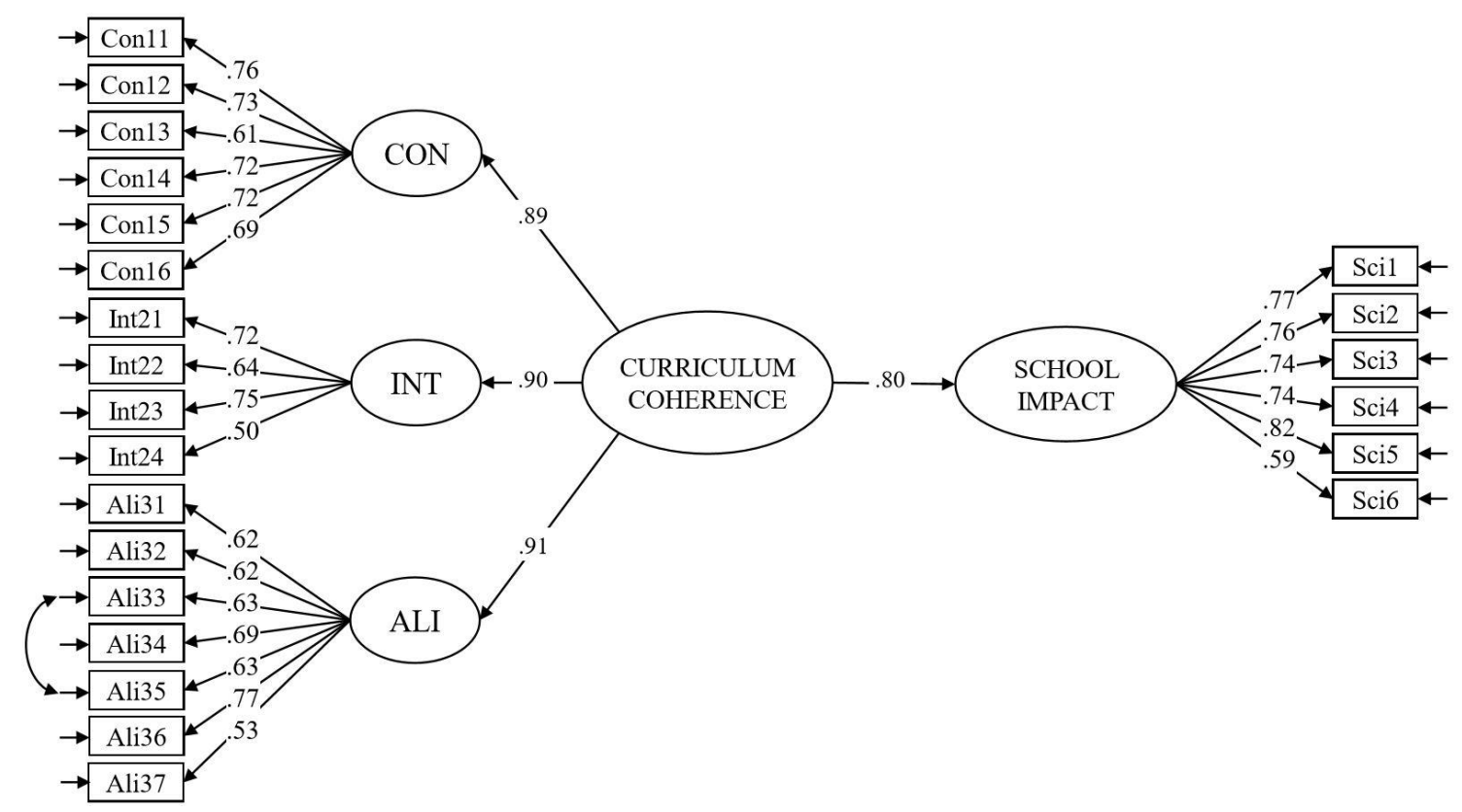

Figure 3. Curriculum coherence as a determinant of school impact. Standardised model: $\mathrm{x}^{2}=469.82, \mathrm{df}=225, \mathrm{p}<.001 ; \mathrm{RMSEA}=.044(90 \%$ C.I. $=.039-.050) ; \mathrm{CFI}=.94 ; \mathrm{TLI}$ $=.93 ; \mathrm{SRMR}=.043$. 